\title{
Measurement properties of the upright motor control test for adults with stroke: a systematic review
}

Edward James R. Gorgon ${ }^{1 *}$ and Rolando T. Lazaro²

\begin{abstract}
Background: The Upright Motor Control Test (UMCT) has been used in clinical practice and research to assess functional strength of the hemiparetic lower limb in adults with stroke. It is unclear if evidence is sufficient to warrant its use. The purpose of this systematic review was to synthesize available evidence on the measurement properties of the UMCT for stroke rehabilitation.
\end{abstract}

Methods: Electronic databases that indexed biomedical literature were systematically searched from inception until October 2015 (week 4): Embase, PubMed, Web of Science, CINAHL, PEDro, Cochrane Library, Scopus, ScienceDirect, SPORTDiscus, LILACS, DOAJ, and Google Scholar. All studies that had used the UMCT in the time period covered underwent hand searching for any additional study. Observational studies involving adults with stroke that explored any measurement property of the UMCT were included. The COnsensus-based Standards for the selection of health Measurement INstruments was used to assess the methodological quality of included studies. The CanChild Outcome Measures Rating Form was used for extracting data on measurement properties and clinical utility.

Results: The search yielded three methodologic studies that addressed criterion-related validity and contruct validity. Two studies of fair methodological quality demonstrated moderate-level evidence that Knee Extension and Knee Flexion subtest scores were predictive of community-level and household-level ambulation. One study of fair methodological quality provided limited-level evidence for the correlation of Knee Extension subtest scores with a laboratory measure of ground reaction forces. No published studies formally assessed reliability, responsiveness, or clinical utility. Limited information on responsiveness and clinical utility dimensions could be inferred from the included studies.

Conclusions: The UMCT is a practical assessment tool for voluntary control or functional strength of the hemiparetic lower limb in standing in adults with stroke. Although different levels of evidence suggest that the Knee Extension and Knee Flexion subtests may possess criterion and construct validity, the lack of published literature examining content validity, reliability, and responsiveness raises questions regarding the use of the UMCT in routine clinical practice. These key findings highlight the need to further investigate the UMCT's measurement properties toward enhancing its standardization.

Keywords: Clinical utility, Clinimetrics, Outcome measure, Reliability, Responsiveness, Validity

\footnotetext{
* Correspondence: ergorgon@up.edu.ph

${ }^{1}$ Department of Physical Therapy, College of Allied Medical Professions,

University of the Philippines, Pedro Gil Street, Malate, Manila 1004,

Philippines

Full list of author information is available at the end of the article
} 


\section{Background}

Significant impairment in lower limb strength is common after a stroke [1]. Impaired lower limb muscle strength is prominent in people who enter inpatient rehabilitation [2] and may persist in all muscle groups years after the stroke [3]. Literature supports the relationship between muscle weakness and post-stroke functional disability, especially in performing critical mobility tasks such as getting out of a chair, standing, walking, and negotiating stairs [1, 4-14]. Accurate evaluation of lower limb muscle weakness is therefore an essential component of effective stroke rehabilitation.

Dynamometry and manual muscle testing (MMT) are common measures of muscle strength. While isometric and isokinetic dynamometry has been demonstrated as an objective method of quantifying isometric and isokinetic strength in adults with stroke $[15,16]$, it requires special instrumentation which may not be feasible in settings where financial resources are limited. MMT was not designed for and cannot be used in persons with central nervous system lesions presenting with muscle tone alterations, abnormal reflex activity, abnormalities in amplitude, timing and scaling of synergistic muscle activity, and abnormal limb movement patterns [17-19]. There is therefore a need to identify a valid and clinically useful method of testing the strength of lower limb muscle groups that will not be limited by the presence of impaired muscle tone or inability to isolate joint movements.

The Upright Motor Control Test (UMCT) [20] or Upright Control (UC) Test [21-23] was originally developed as a clinician-administered clinical test of voluntary control of the affected lower limb in standing toward predicting functional walking ability in adults with stroke [C. Toman, unpublished thesis]. It is quick and simple to administer, requires no instrumentation and minimal physical space, and is therefore suitable for any clinical setting [24]. Clinically, it has been used to identify the presence of lower limb dyscontrol or muscle weakness in stroke [21, 23, 25, 26] and other neurological conditions [22, 24, 27]; and/or to measure stroke rehabilitation outcomes in longitudinal studies $[19,28]$, including clinical trials [29-31]. Since it is practical to administer and can be used on patients with muscle tone abnormalities and impairments in selective movement control from central nervous system lesions [20], it addresses the limitations related to dynamometry and MMT.

The UMCT provides information on the ability to bear weight on and unload the affected lower limb in standing $[19,20]$. The test can also assess both muscle force and muscle activation [19]. Weight bearing or extension control is assessed at the hip, knee, and ankle in the single-limb stance position (Fig. 1) [20], therefore simulating the limb loading requirements during stance phase of gait [C. Toman, unpublished thesis]. Unloading or flexion control is also assessed at the hip, knee, and ankle, while the contralateral lower limb is in singlelimb stance [20]. The UMCT subtests, as well as the specific, required movements of the patient to complete the subtests, are detailed in Table 1.

Generally, three Extension Control (Hip Extension, Knee Extension, and Ankle Extension) and two Flexion

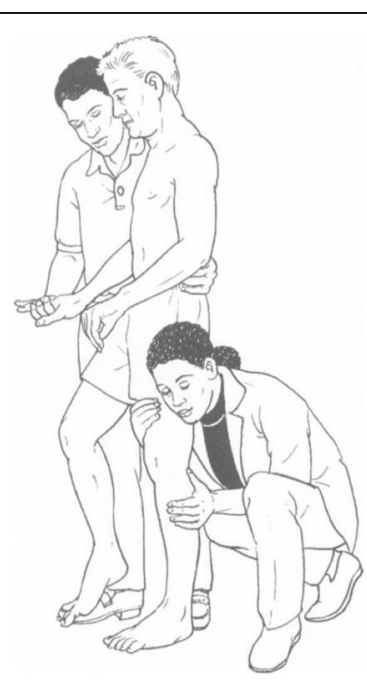

(A)

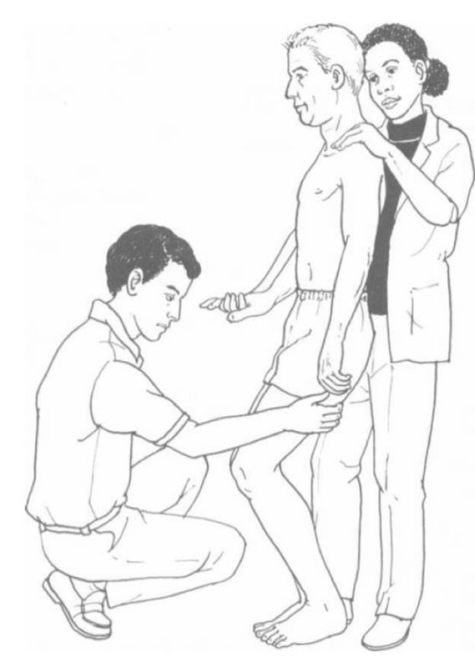

(B)

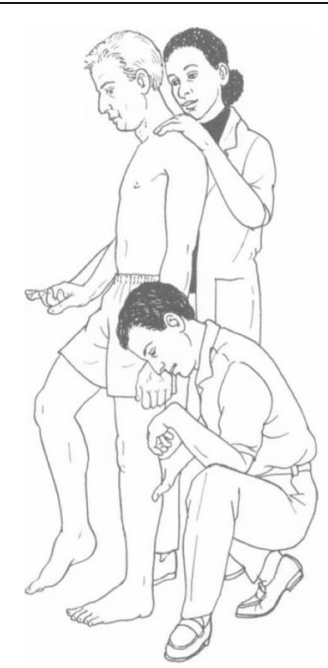

(C)

Fig. 1 Upright Motor Control Test extension subtests. The UMCT comprises six extension and flexion subtests intended to reflect the limb loading and unloading demands of upright functional activities such as walking. Figure illustrates the extension subtests: hip extension (a), knee extension (b), and ankle plantarflexion (c). Reprinted with permission: Daniels and Worthingham's Muscle Testing: Techniques of Manual Examination, 8th edition, Hislop HJ, Montgomery J, Upright Motor Control, pages 343-350, Copyright Elsevier (2007) [20] 
Table 1 Upright motor control test components, subtest tasks, and scoring criteria

\begin{tabular}{|c|c|c|c|}
\hline Test component & $3=$ Strong & $2=$ Moderate & $1=$ Weak \\
\hline \multicolumn{4}{|l|}{ Extension Control Test } \\
\hline $\begin{array}{l}\text { Hip Extension } \\
\text { Patient's task: Stand on the weaker } \\
\text { leg only and keep the body as } \\
\text { straight as possible. }\end{array}$ & $\begin{array}{l}\text { Maintains trunk erect } \\
\text { on hip in single-leg stance }\end{array}$ & $\begin{array}{l}\text { Unable to maintain trunk erect, } \\
\text { but able to stop forward trunk } \\
\text { momentum OR trunk wobbles } \\
\text { back and forth OR trunk } \\
\text { hyperextends on hip }\end{array}$ & $\begin{array}{l}\text { Unable to control trunk flexion } \\
\text { on hip in single-leg stance }\end{array}$ \\
\hline $\begin{array}{l}\text { Knee Extension } \\
\text { Patient task: Stand on both legs } \\
\text { with the knees bent, lift the } \\
\text { stronger leg while the knee of } \\
\text { the weaker leg remains bent, } \\
\text { then straighten the knee of the } \\
\text { weightbearing leg. }\end{array}$ & $\begin{array}{l}\text { Supports body weight on } \\
\text { flexed knee and straightens } \\
\text { knee to end of range on } \\
\text { command }\end{array}$ & $\begin{array}{l}\text { Supports body weight on flexed } \\
\text { knee (no further collapse } \\
\text { into flexion) }\end{array}$ & $\begin{array}{l}\text { Unable to maintain body weight } \\
\text { on flexed knee (knee collapses } \\
\text { in flexion) }\end{array}$ \\
\hline $\begin{array}{l}\text { Ankle Extension (Plantarflexion) } \\
\text { Patient task: Stand on both legs } \\
\text { with the knees straight, lift the } \\
\text { stronger leg while the tibia of } \\
\text { the weaker leg remains vertical, } \\
\text { then raise the heel of the weaker } \\
\text { leg as high as possible. }\end{array}$ & $\begin{array}{l}\text { Maintains knee at neutral } \\
\text { and lifts heel off floor on } \\
\text { command }\end{array}$ & $\begin{array}{l}\text { Can control knee at } 0^{\circ} \text { and ankle } \\
\text { at } 90^{\circ} \text { with tibia vertical }\end{array}$ & $\begin{array}{l}\text { Knee flexed, ankle dorsiflexed so } \\
\text { that tibia displaces forward in } \\
\text { single-leg stance }\end{array}$ \\
\hline \multicolumn{4}{|l|}{ Flexion Control Test } \\
\hline $\begin{array}{l}\text { Hip Flexion } \\
\text { Patient task: Bring the knee up } \\
\text { toward the chest, as high and } \\
\text { as fast as possible, while standing } \\
\text { straight. }\end{array}$ & $\begin{array}{l}\text { Actively flexes }>60^{\circ}, 3 \text { rep } \\
\text { within } 10 \mathrm{~s}\end{array}$ & $\begin{array}{l}\text { Acively flexes } 30-60^{\circ}, 3 \text { rep } \\
\text { within } 10 \mathrm{~s}\end{array}$ & $\begin{array}{l}\text { No motion OR actively flexes } \\
<30^{\circ}, 3 \text { rep taking }>10 \mathrm{~s}\end{array}$ \\
\hline $\begin{array}{l}\text { Knee Flexion } \\
\text { Patient task: Bring the knee up } \\
\text { toward the chest three times, as } \\
\text { high and as fast possible, while } \\
\text { standing straight. }\end{array}$ & $\begin{array}{l}\text { Actively flexes }>60^{\circ}, 3 \text { rep } \\
\text { within } 10 \mathrm{~s}\end{array}$ & $\begin{array}{l}\text { Actively flexes } 30-60^{\circ}, 3 \text { rep } \\
\text { within } 10 \mathrm{~s}\end{array}$ & $\begin{array}{l}\text { No motion OR actively flexes } \\
<30^{\circ}, 3 \text { rep taking }>10 \mathrm{~s}\end{array}$ \\
\hline $\begin{array}{l}\text { Ankle Flexion (Dorsiflexion) } \\
\text { Patient task: Bring the knee and } \\
\text { foot up toward the chest as high } \\
\text { and as fast as possible, while } \\
\text { standing straight. }\end{array}$ & $\begin{array}{l}\text { Actively dorsiflexes } \geq 90^{\circ} \text {, } \\
3 \text { rep within } 10 \mathrm{~s}\end{array}$ & Not used & $\begin{array}{l}\text { No motion OR actively dorsiflexes } \\
<90^{\circ}, 3 \text { rep taking }>10 \mathrm{~s}\end{array}$ \\
\hline
\end{tabular}

Adapted from Hislop \& Montgomery [20]

Control (Hip Flexion and Knee Flexion) subtests are rated on a three-point ordinal scale with the following muscle grade categories: Strong, Moderate, and Weak [20] (Table 1). The Ankle Flexion (Dorsiflexion) subtest comprises only two muscle grade categories: Strong and Weak. Subscale scores (Strong $=3$, Moderate $=2$, and Weak =1) may be interpreted individually, as a combined extension or flexion score, or total (combined extension and flexion) score [C. Toman, unpublished thesis]. An additional category, Excessive, is applied for the knee extension and ankle extension (plantaflexion) subtests in cases of severe muscle tone impairment that preclude placing the test knee in flexion or the test ankle in plantigrade position [20]. To administer the UMCT, the clinician typically stands facing the patient, demonstrates each subtest to the patient to promote understanding, provides one or two practice trials, then observes and rates the patient's performance based on the scoring criteria. Apart from being highly practical to administer, the UMCT also has a simple and welldefined scoring system.

Despite its advantages over conventional tests of muscle strength, little is known about the measurement properties of the UMCT for the population of patients with stroke. For a test to be acceptable for widespread use in both clinical practice and research, it must exhibit appropriate measurement or clinimetric properties such as reliability, validity, and responsiveness [32, 33]. This issue underscores the need to ascertain the usefulness of the UMCT in evaluating motor impairment and monitoring change over time to assess the impact of interventions. Therefore, the main purpose of this systematic review was to synthesize the available published literature on the measurement properties of the UMCT when used in adults with stroke. The review findings were projected to help in identifying research gaps that may warrant additional work to further develop and standardize the UMCT. 


\section{Method}

\section{Search strategy}

Multiple electronic databases containing peer-reviewed literature were systematically searched from inception until October 2015 (week 4): Embase, PubMed, Web of Science, CINAHL, PEDro, Cochrane Library, Scopus, ScienceDirect, SPORTDiscus, LILACS, DOAJ, and Google Scholar. Keyword searching used the exact terms "upright motor control" and "upright control test", which were the specific terms used to refer to the UMCT. All articles that described use of the UMCT, including any related literature review, underwent hand searching to locate additional studies. No restrictions were placed on publication language.

\section{Study selection}

Two independent researchers (EJRG) and a trained research assistant (AL) implemented the search strategy, including full text examination of relevant studies. All titles and abstracts were screened, and all potentially relevant articles underwent full text examination. Peerreviewed or published research articles reporting on measurement properties of the UMCT for adults (aged higher than 18 years) with stroke were included. Relevant studies were observational-methodologic in nature [34]. Exclusion criteria were: (1) study did not have an available full report or was available only as an abstract, such as publications in conference proceedings; (2) sample was a mix of neurological conditions with no separate clinimetric estimates reported for participants with stroke. To settle any disagreement, it was pre-planned that the independent researchers would re-examine the full-text article before arriving at a consensus.

\section{Quality assessment}

The first author (EJRG) appraised data from the included studies using the COnsensus-based Standards for the selection of health Measurement INstruments (COSMIN) [35]. The COSMIN checklist comprises standardized criteria for evaluating the quality of methodological studies included in systematic reviews. Measurement properties that can be assessed on the COSMIN include: reliability, which is subdivided into internal consistency, reliability, and measurement error; validity, which comprises content validity (includes face validity), construct validity (covers structural validity, hypothesis testing, and cross-cultural validity), and criterion validity; and responsiveness. Each measurement property is examined using a number of quality criteria, with criteria pertaining to sample size and missing values being common across all the properties. Each item is rated on a fourpoint ordinal scale as "excellent", "good", "fair", or "poor". The COSMIN operates on the principle of "worst score counts", i.e. the overall methodological quality score is determined by identifying the lowest or worst score among the items on the checklist [36]. The second author (RTL) independently verified the quality assessment. It was pre-planned that, should any disagreement arise, both authors would re-examine the article full text to arrive at a consensus.

\section{Data extraction}

The first author (EJRG) performed data extraction using the CanChild Outcome Measures Rating Form [37]. This measure contains fields for extracting data on the measurement instrument's focus based on the International Classification of Functioning, Disability and Health (ICF) [38]; scale construction; clinical utility; and standardization related to reliability, validity, and responsiveness. Additional information extracted from the selected studies include authors and publication year; test components assessed; purpose for applying the test; and sample characteristics such as sample size, age, gender, side of stroke, type of stroke based on etiology and chronicity, and functional status or severity of motor impairment. To enhance the accuracy of data extraction, explicit definitions of the measurement properties based on the COSMIN [39] were adopted (Table 2). The second author (RTL) independently verified the data extraction. As with quality assessment, for any disagreement that would arise, it was pre-planned that both authors would reexamine the full-text and arrive at a consensus.

\section{Data analysis and synthesis}

The authors performed a best evidence synthesis based on the COSMIN guidelines. For each measurement property, the possible overall rating was "positive", "indeterminate", or "negative" (Table 2) [40]. This overall rating was accompanied by an assessment of the level of evidence based on the work of the Cochrane Back Review Group: "strong", "moderate", "limited", “conflicting", or "unknown" (Table 3) [41]. The levels of evidence are determined based on the number of studies that have investigated the measurement property, methodological quality of such studies, and consistency of the results of such studies.

\section{Results}

\section{Search results}

The search yielded a total of 275 citations (Fig. 2). Since use of single keywords generated manageable search yields, use of keyword combinations was unnecessary. Initial screening was done to remove duplicates. Next, abstracts were examined to exclude studies that did not investigate any measurement property of the UMCT. Following this step, five titles remained for full-text review. Two articles were further excluded because one 
Table 2 Definitions of and standards used to interpret measurement properties

\begin{tabular}{|c|c|c|}
\hline Property & Definition [39] & Standard for interpretation [40] \\
\hline Reliability & $\begin{array}{l}\text { The extent to which scores for patients who have not } \\
\text { changed are the same for repeated measurement under } \\
\text { several conditions: e.g. over time (test-retest); by different } \\
\text { persons on the same occasion (inter-rater) or by the same } \\
\text { persons (i.e. raters or responders) on different occasions } \\
\text { (intra-rater) }\end{array}$ & $\begin{array}{l}+=I C C \text { or weighted Kappa } \geq 0.70 \\
?=\text { Doubtful design or method (e.g. time interval not } \\
\text { mentioned) } \\
-=\text { ICC or weighted Kappa }<0.70, \text { despite adequate } \\
\text { design and method }\end{array}$ \\
\hline $\begin{array}{l}\text { Validity: Construct validity } \\
\text { (hypotheses testing) }\end{array}$ & $\begin{array}{l}\text { The degree to which the scores of a measurement are } \\
\text { consistent with hypotheses (for instance with regard to } \\
\text { internal relationships, relationships to scores of other } \\
\text { instruments or differences between relevant groups) based } \\
\text { on the assumption that the measurement validity measures } \\
\text { the construct to be measured }\end{array}$ & $\begin{array}{l}+=\text { Correlation with an instrument measuring the same } \\
\text { construct } \geq 0.50 \text { OR at least } 75 \% \text { of the results are in } \\
\text { accordance with these hypotheses AND correlation with } \\
\text { related constructs is higher than with unrelated constructs } \\
?=\text { = Solely correlations determined with unrelated constructs } \\
-=\text { Correlation with an instrument measuring the same } \\
\text { construct }<0.50 \text { OR }<75 \% \text { of the results are in accordance } \\
\text { with the hypotheses OR correlation with related constructs } \\
\text { is lower than with unrelated constructs }\end{array}$ \\
\hline Validity: Criterion validity & $\begin{array}{l}\text { The degree to which the scores of a measurement are } \\
\text { an adequate reflection of a "gold standard" }\end{array}$ & $\begin{array}{l}+=\text { Convincing arguments that gold standard is "gold" AND } \\
\text { correlation with gold standard } \geq 0.70 \\
\text { ? No convincing arguments that gold standard is "gold" OR } \\
\text { doubtful design or method } \\
-=\text { Correlation with gold standard }<0.70 \text {, despite adequate } \\
\text { design and method }\end{array}$ \\
\hline Responsiveness & $\begin{array}{l}\text { The ability of a measurement to detect change over time } \\
\text { in the construct to be measured }\end{array}$ & $\begin{array}{l}+=\text { Correlation with an instrument measuring the same } \\
\text { construct } \geq 0.50 \text { OR at least } 75 \% \text { of the results are in } \\
\text { accordance with these hypotheses OR AUC } \geq 0.70 \text { AND } \\
\text { correlation with related constructs is higher than with } \\
\text { unrelated constructs } \\
?=\text { Solely correlations determined with unrelated constructs } \\
-=\text { Correlation with an instrument measuring the same } \\
\text { construct }<0.50 \text { OR }<75 \% \text { of the results are in accordance } \\
\text { with the hypotheses OR AUC }<0.70 \text { OR correlation with } \\
\text { related constructs is lower than with unrelated constructs }\end{array}$ \\
\hline
\end{tabular}

ICC intraclass correlation coefficient, AUC area under the curve, + positive rating, ? indeterminate rating, - negative rating

Doubtful design or method = lacks clear description of study design or methods; used sample size smaller than 50 participants; or any important methodological flaw in study design or implementation

study used the UMCT as a descriptive measure only and did not explore any aspect of instrument development [21], and the other study investigated interrater reliability but was published only as a conference abstract with no full report available [42]. Three studies examined the UMCT's measurement properties [43-45] and were included in the qualitative synthesis. The researchers were in full agreement on the selection of the final studies to be included.

Table 3 Levels of evidence for quality of measurement properties proposed by Cochrane Back Review Group

\begin{tabular}{|c|c|c|}
\hline Level & Rating & Criterion \\
\hline Strong & +++ or - & $\begin{array}{l}\text { Consistent findings in multiple studies of good } \\
\text { methodological quality OR in one study of } \\
\text { excellent methodological quality }\end{array}$ \\
\hline Moderate & ++ or - & $\begin{array}{l}\text { Consistent findings in multiple studies of fair } \\
\text { methodological quality OR in one study of } \\
\text { good methodological quality }\end{array}$ \\
\hline Limited & + or - & One study of fair methodological quality \\
\hline Conflicting & $+/-$ & Conflicting findings \\
\hline Unknown & $?$ & Only studies of poor methodological quality \\
\hline
\end{tabular}

+ positive rating, ? indeterminate rating, - negative rating

Adapted from van Tulder et al. [41]

\section{Included studies}

Table 4 shows the characteristics of the participants in the included studies. Sample sizes ranged from 33147 adults with stroke, while mean ages ranged from 53.9-58.73 years. Samples had a mix of genders, sides of hemiplegia, and types of stroke based on etiology (ischemic and hemorrhagic). Two studies included both subacute and chronic stroke populations [43, 44 ], while one study included only patients with subacute stroke (30-180 days post-onset) [45].

\section{Quality assessment}

Given the COSMIN's use of the "worst score counts" principle, all studies had an overall rating of "fair" (Table 5). The Criterion validity subscale was used to assess the two studies on predictive validity [43,44], while the Hypothesis testing (Construct validity) subscale was used on the study on convergent validity [45]. Evidence for criterion validity was positive but the two supporting studies shared similar limitations. Both had insufficient description of missing data and information to justify the choice of the gold standard, therefore resulting in a "fair" quality rating [43, 44]. Evidence for construct validity, though positive, was limited by the supporting 


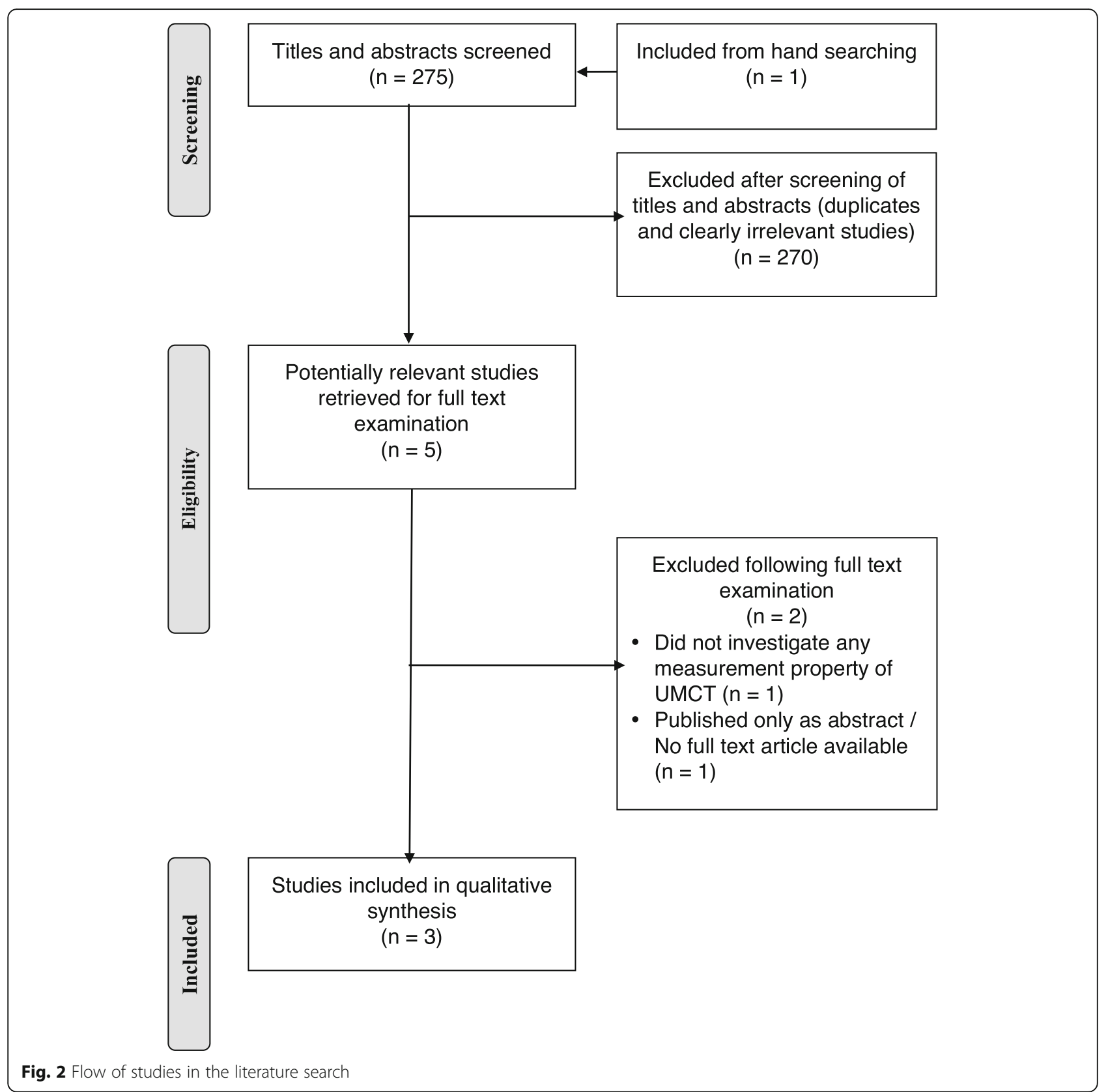

study's lack of a clear a priori hypothesis, and insufficient description of the comparator instrument and its measurement properties [45]. Therefore, a "fair" quality rating was given.

\section{Data extraction and synthesis}

Table 4 summarizes the results of the included studies. One study covered all six Extension Control and Flexion Control subtests [44]; one delimited investigation to the Knee Extension and Knee Flexion subtests only [43]; and one focused on the Knee Extension subtest only [45]. The studies used the UMCT as a test of voluntary control $[43,45]$ or functional strength [44] of the affected lower limb, covering the Body Functions dimension of the ICF framework (Power of Muscles of One Side of the Body, ICF code b7302) [38]. The three studies addressed dimensions of validity, but none assessed reliability. None of the published studies addressed content validity, particularly aspects of scale construction such as selection of test items for inclusion and weighting of items in scoring. One study described some observations regarding responsiveness [45], while two studies provided information related to some clinical utility dimensions [43, 45].

Two studies on criterion (predictive) validity reported similar findings that the Knee Extension and Knee 
Table 4 Characteristics and findings of included studies on upright motor control test measurement properties

\begin{tabular}{|c|c|c|c|c|c|}
\hline Authors & Participants & Test component assessed & Purpose of test application & Validity & Clinical utility \\
\hline Joa et al. [43] & $\begin{array}{l}124 \text { adults with subacute } \\
\text { and chronic strokes ( } 56 \text { F; } \\
73 \text { ischemic stroke; } 68 \text { left } \\
\text { hemiplegia) } \\
\text { Age }=53.9 \text { (SD 15.4) yr } \\
66 \text { community walkers; } \\
58 \text { household walkers }\end{array}$ & Knee Extension, Knee Flexion & $\begin{array}{l}\text { To test voluntary control } \\
\text { of hemiparetic lower limb }\end{array}$ & $\begin{array}{l}\text { Criterion validity (diagnostic accuracy) assessed } \\
\text { Subtests predictive of community-level ambulation } \\
\text { versus home-level ambulation } \\
\text { - Score of } 3 \text { (Strong score) for either Knee Extension } \\
\text { or Knee Flexion predicted community ambulation } \\
\text { - Score of } 1 \text { or } 2 \text { (Weak or Moderate score) for both } \\
\text { Knee Extension and Knee Flexion predicted household } \\
\text { ambulation } \\
\text { Sensitivity, specificity, and AUC for identifying restriction } \\
\text { in community ambulation } \\
\text { - UMCT alone: } 98 \%, 67 \% \text {, and } 0.829 \\
\text { - UMCT combined with Korean BBS: } 81 \%, 93 \% \text {, and } 0.875 \\
\text { - UMCT combined with gait velocity: } 89 \%, 91 \% \text {, and } 0.904 \\
\text { - UMCT combined with Korean BBS and gait velocity: } 80 \% \text {, } \\
94 \% \text {, and } 0.876\end{array}$ & $\begin{array}{l}\text { Does not require equipment } \\
\text { Takes approximately } 1 \text { min to } \\
\text { complete (each test) }\end{array}$ \\
\hline Perry et al. [44] & $\begin{array}{l}147 \text { adults with subacute } \\
\text { and chronic strokes ( } 79 \text { F; } \\
\text { different etiologies; } 79 \text { left } \\
\text { hemiplegia) } \\
\text { Age }=55.5 \text { (SD 12.2) yr } \\
78 \text { community walkers; } \\
69 \text { household walkers }\end{array}$ & $\begin{array}{l}\text { All } 6 \text { components of } \\
\text { Extension Control Test and } \\
\text { Flexion Control Test }\end{array}$ & $\begin{array}{l}\text { To test functional muscle } \\
\text { strength of hemiparetic } \\
\text { lower limb }\end{array}$ & $\begin{array}{l}\text { Criterion validity (predictive validity) assessed } \\
\text { Composite scores not significantly different across } 6 \\
\text { functional walking categories } \\
\text { Scores on Knee Extension and Knee Flexion predictive of } \\
\text { community-level ambulation versus home-level ambulation } \\
\text { - } 78 \% \text { accuracy, } 78 \% \text { agreement } \\
\text { - Score of } 3 \text { (Strong score) for either Knee Extension or Knee } \\
\text { Flexion predicted community ambulation } \\
\text { - Score of } 1 \text { or } 2 \text { (Weak or Moderate score) for both Knee } \\
\text { Extension and Knee Flexion predicted household ambulation } \\
\text { - Knee Extension subtest combined with gait velocity: } 87 \% \\
\text { agreement with expert clinicians in differentiating between } \\
\text { community ambulators and household ambulators } \\
\text { - Score of } 3 \text { (Strong score) for Knee Extension with gait } \\
\text { velocity of at least } 16 \mathrm{~m} / \text { min predicted community } \\
\text { ambulation } \\
\text { - Scores of } 1 \text { and } 2 \text { (Moderate and Weak scores) for Knee } \\
\text { Extension with gait velocities lower than } 32 \mathrm{~m} / \text { min and } \\
24 \mathrm{~m} / \mathrm{min} \text { respectively predicted household ambulation }\end{array}$ & $\begin{array}{l}\text { No specific information } \\
\text { provided }\end{array}$ \\
\hline Mercer et al. [45] & $\begin{array}{l}33 \text { adults with subacute } \\
\text { stroke (15 F; } 23 \text { left } \\
\text { hemiplegia); } 25 \text { completing } \\
\text { all } 6 \text { testing sessions } \\
\text { Age }=58.73 \text { (SD 17.27) yr } \\
\text { Baseline FMA lower limb } \\
\text { motor scale score }=17.82 \\
\text { (SD 6.22) }\end{array}$ & Knee Extension & $\begin{array}{l}\text { To test voluntary control } \\
\text { of hemiparetic lower limb }\end{array}$ & $\begin{array}{l}\text { Construct validity (convergent validity) assessed } \\
\text { Positive correlations between Knee Extension scores and } \\
\text { paretic-limb peak vertical GRF (pseudo R2) } \\
\cdot 0.34 \text {, during stepping with non-paretic limb } \\
\cdot 0.22 \text {, during diagonal reach task } \\
\cdot 0.21 \text { = during sit-to-stand task }\end{array}$ & $\begin{array}{l}\text { Easily administered in a } \\
\text { variety of clinical settings }\end{array}$ \\
\hline
\end{tabular}

$\overline{A U C}$ area under the received operator characteristic curve, BBS Berg Balance Scale, FMA Fugl-Meyer Assessment, GRF ground reaction force, ST Step Test, UMCT Upright Motor Control Test 
Table 5 Methodological quality of included studies and levels of evidence for quality of measurement property

\begin{tabular}{llll}
\hline Study & Hypothesis testing (Construct validity) & Criterion validity & Reliability \\
\hline Joa et al. [43] & & Fair / ++ & Responsiveness \\
Perry et al. [44] & Fair / ++ & \\
Mercer et al. [45] & Fair / - & Moderate & \\
Level of evidence & Limited & L
\end{tabular}

Level of evidence [41]: Strong = consistent findings in multiple studies of good methodological quality OR in one study of excellent; Moderate = consistent findings in multiple studies of fair methodological quality OR in one study of good methodological quality; Limited = one study of fair methodological quality methodological quality; Conflicting = Conflicting findings; Unknown = Only studies of poor methodological quality

+ positive rating, ? indeterminate rating, - negative rating

Flexion subtests differentiated between community and household ambulators [43, 44]. Both studies demonstrated that a Strong score on either subtests could be used to identify community ambulators while a Moderate or Weak score on both subtests could be used to identify household ambulators. Further, both studies demonstrated the predictive ability of the knee subtests when combined with other clinical measures such as gait velocity $[43,44]$ and the Korean version of the Berg Balance Scale (BBS) [43]. A Strong score on the Knee Extension subtest combined with a minimum gait velocity of $16 \mathrm{~m} / \mathrm{min}$ characterized community ambulators in one study [44], while the knee subtests, applied alone or with either or both gait velocity or the BBS, yielded areas under the receiver operating characteristic curve (AUC) of $0.829-0.904$ in the other study [43]. One study on construct (convergent) validity found that Knee Extension scores positively correlated with peak vertical ground reaction force measurements during limb loading tasks such as sit-to-stand, diagonal reaching, and stepping with the non-paretic lower limb (psuedo $R^{2}=$ $0.21-0.34$ ) [45]. The levels of evidence represented by the included studies were "moderate" for criterion validity and "limited" for construct validity (Table 5).

Although none of the studies formally assessed responsiveness and clinical utility, data were available related to these properties. One study reported that improving Knee Extension scores were related to increasing Step Test scores over the first 6 months poststroke [45]. From $73 \%(24 / 32)$ at 1 month post-stroke, the proportion of participants with a score of 1 (Weak score) decreased to $31 \%(9 / 29)$ at 6 months post-stroke. From $12 \%(4 / 32)$ at 1 month post-stroke, the proportion of participants with a score of 3 (Strong score) rose to $55 \%(16 / 29)$ at 6 months post-stroke. In the same study, floor and ceiling effects were also reported, with $27 \%$ $(9 / 33)$ of participants not improving from a Weak score even after 6 months and $36 \%(12 / 33)$ achieving the highest score (Strong score) before the last testing session. Two studies mentioned data addressing some clinical utility dimensions: ease of administration [45]; no special equipment required [43]; and short administration time [43].

\section{Discussion}

This review synthesized the evidence on the measurement properties of the UMCT from three studies on validity [43-45] located through a comprehensive literature search. Best evidence synthesis indicates that there is moderate level of evidence to support criterion validity of the Knee Extension and Knee Flexion subtests and limited level of evidence for construct validity of the Knee Extension subtest. The results of this synthesis, together with the lack of literature formally assessing content validity, reliability, and responsiveness, provide an important basis for evaluating the current usefulness of the UMCT as well as identifying important knowledge gaps for further research.

Evidence for different dimensions of validity synthesized in this systematic review is consistent with the original work on the UMCT. Validity of the UMCT was first examined in 1983 in an unpublished master's thesis [C. Toman, personal communication]. In that study, relationships between the UMCT score (then called the UC Test) and gait variables were evaluated in 20 adults with subacute or chronic stroke. Total UC scores from the 6 subtests correlated significantly with important gait parameters such as gait velocity, stride length, and single-limb support time in the hemiparetic lower limb. This significant correlation with gait parameters is in keeping with moderate-level evidence from this review that the UMCT, specifically the Knee Extension and Knee Flexion subtests, can be used to predict walking ability in adults with subacute or chronic stroke [43, 44].

In one study [43], when the Knee Extension and Knee Flexion subtests were used either alone or in combination with gait velocity, the BBS, or both, the range of AUC values reported suggests at least moderate accuracy [46] in separating individuals with walking restrictions (household ambulators) from those without walking restrictions (community ambulators). Therefore, the available evidence is in agreement with the assertion of Perry et al. that the knee subtests may represent a valid method of assessing voluntary total limb control in standing [44]. Still, however, the exact process employed in the development of the UMCT's subtests and scales, and 
interpretation of cumulative scores remain unclear and therefore warrants examination for content validity.

The absence of published reports on the UMCT's reliability has important negative ramifications on the accuracy of its validity estimates. Reliability estimates for the UMCT when used on patients with stroke-related hemiplegia have been mentioned in earlier work involving clinicians [J. Montgomery, unpublished data] or students [42], however such work was never published in a peerreviewed journal. Thus, sufficient study appraisal and data extraction could not be carried out. Without interrater reliability estimates, it is uncertain if measurements would be stable across different raters. In practice, clinicians who might use the UMCT would likely possess varied clinical practice experience and the impact of such differences in practice experience would be important to know. Also, without test-retest reliability estimates, it is unclear if measurements would be stable in longitudinal assessment in the absence of real change from either spontaneous recovery or the effects of intervention. This key research gap highlights the need to examine the interrater and testretest reliability of the UMCT in adults with stroke.

The lack of studies that formally assess responsiveness can have a negative impact on the UMCT's value in longitudinal assessment. Limited data from one study suggests that, although scores on the Knee Extension subtest may change over time, possible floor and ceiling effects can be observed [45]. This finding may be related to the few scale levels available for scoring which might diminish the instrument's ability to detect small changes in performance. One clinical trial [31] has demonstrated that scores on the UMCT can significantly change over time in adults with stroke exposed to an active treatment compared to those exposed to placebo. However, studies on effectiveness of interventions are inappropriate when demonstrating responsiveness [39]. Studies that can demonstrate that scores on the test of interest (i.e. $\mathrm{UMCT}$ ) change correspondingly with scores on a test that is considered a gold standard would be more appropriate for addressing the knowledge gap [39]. Such studies are important in light of research literature in which the UMCT has been used in longitudinal assessment.

Although no study has formally assessed clinical utility, data inferred from existing literature indicate that features of UMCT administration are consistent with known features of highly practical tests in clinical practice [37]. This finding highlights an important advantage of the UMCT over measures that are well established but require expensive instrumentation that preclude use in many clinical settings such as dynamometry. Additionally, the available studies on the UMCT's measurement properties did not require the exclusion of participants who were incapable of selective limb control. This feature emphasizes a key advantage of the
UMCT over extensively used tools such as dynamometry and MMT. Thus, current evidence on measurement properties and practicality of test administration provide an argument for the potential of the UMCT to be further developed and standardized.

This systematic review has limitations. At the review level, few published studies have investigated the measurement properties of the UMCT to date. Thus, firm conclusions regarding most of the UMCT's properties, especially content validity, reliability, and responsiveness, cannot be made at this point. At the study level, the available studies have reported on the properties of the Knee Extension [43-45] and Knee Flexion subtests $[43,44]$ only, and the methodological quality of the studies was fair [43-45]. Although the Knee Extension subtest procedure and scoring was applied consistently across the three studies [43-45], the Moderate score of the Knee Flexion subtest was omitted in one of the two studies that examined it [44]. Therefore, further enhancement of the methodological quality of studies and clarification of the application of the scoring method are warranted.

\section{Conclusion}

Findings of this systematic review indicate that in adults with subacute and chronic types of stroke, moderate evidence from two studies supports that the Knee Extension and Knee Flexion subtests of the UMCT can potentially identify adults with restrictions in functional walking. Further, in adults with subacute stroke, limited evidence from one study suggests that the Knee Extension subtest positively correlates with weight bearing. Since no instrumentation is needed, administration is easy, and time and space requirements are minimal, it is feasible for clinicians to routinely apply the UMCT in practice. However, its use in clinical practice and research is limited by the absence of published data on content validity, reliability, and responsiveness. Further research should assess these important measurement properties of the UMCT to support its integration in stroke rehabilitation.

\section{Abbreviations \\ AUC: Areas under receiver operating characteristic curve; BBS: Berg balance scale; COSMIN: COnsensus-based Standards for the selection of health Measurement INstruments; ICF: International classification of functioning, disability and health; MMT: Manual muscle testing; UC: Upright control; UMCT: Upright motor control test}

\section{Acknowledgments}

The authors acknowledge the contributions of Charles Toman in providing additional information on the UMCT and Alma Labro in independent literature searching. This work was presented as a research poster at the Combined Sections Meeting of the American Physical Therapy Association in February 2016 in Anaheim, California. The authors thank the alumni of the University of the Philippines Manila - College of Allied Medical Professions who provided support to EJRG in disseminating this work. 


\section{Funding}

No funding was received for this study.

\section{Availability of data and materials}

All data generated or analysed during this study are included in this published article.

\section{Authors' contributions}

EJRG conceived and designed the systematic review. EJRG and RTL abstracted, appraised, and synthesized the data; prepared the manuscript; and approved all versions of the manuscript submitted to the journal.

\section{Competing interests}

The authors declare that they have no competing interests.

\section{Consent for publication}

Not applicable.

\section{Ethics approval and consent to participate}

Not applicable.

\section{Author details}

'Department of Physical Therapy, College of Allied Medical Professions, University of the Philippines, Pedro Gil Street, Malate, Manila 1004. Philippines. ${ }^{2}$ Department of Physical Therapy, Samuel Merritt University, 450 30th Street 3726, Oakland, CA 94609, USA.

\section{Received: 4 July 2016 Accepted: 31 October 2016}

\section{Published online: 08 November 2016}

\section{References}

1. Bohannon RW. Muscle strength and muscle training after stroke. J Rehabil Med. 2007;39:14-20.

2. Andrews AW, Bohannon RW. Short-term recovery of limb muscle strength after acute stroke. Arch Phys Med Rehabil. 2003;84:125-30.

3. Dorsch S, Ada L, Canning CG. Lower limb strength is significantly impaired in all muscle groups in ambulatory people with chronic stroke: a crosssectional study. Arch Phys Med Rehabil. 2016;97:522-7.

4. Cameron DM, Bohannon RW, Garrett GE, Owen SV, Cameron DA. Physical impairments related to kinetic energy during sit-to-stand and curb-climbing following stroke. Clin Biomech. 2003;18:332-40.

5. Bohannon RW. Correlation of lower limb strengths and other variables with standing performance in stroke patients. Physiother Can. 1989;41:198-202.

6. Marigold DS, Eng JJ, Tokuno CD, Donnelly CA. Contribution of muscle strength and integration of afferent input to postural instability in persons with stroke. Am Soc Neurorehabil. 2004;18:222-9.

7. Kluding P, Gajewski B. Lower-extremity strength differences predict activity limitations in people with chronic stroke. Phys Ther. 2009;89:73-81.

8. Kim CM, Eng JJ. The relationship of lower-extremity muscle torque to locomotor performance in people with stroke. Phys Ther. 2003;83:49-57.

9. Bohannon RW. Correlation of knee extension force and torque with gait speed in patients with stroke. Physiother Theory Pract. 1991;7:185-90.

10. Nakamura R, Watanabe S, Handa T, Morohashi I. The relationship between walking speed and muscle strength for knee extension in hemiparetic stroke patients: a follow-up study. Tohoku J Exp Med. 1988;154:111-3.

11. Nadeau S, Arsenault AB, Gravel D, Bourbonnais D. Analysis of the clinical factors determining natural and maximal gait speeds in adults with a stroke. Am J Phys Med Rehabil. 1999;78:123-30

12. Suzuki K, Imada G, Iwaya T, Handa T, Kurogo H. Determinants and predictors of the maximum walking speed during computer-assisted gait training in hemiparetic stroke patients. Arch Phys Med Rehabil. 1999;80:179-82.

13. Suzuki K, Nakamura R, Yamada Y, Handa T. Determinants of maximum walking speed in hemiparetic stroke patients. Tohoku J Exp Med. 1990;162: 337-44.

14. Bohannon RW, Walsh S. Association of paretic lower extremity muscle strength and standing balance with stair-climbing ability in patients with stroke. J Stroke Cerebrovasc Dis. 1991;1:129-33.

15. Mong Y, Teo TW, Ng SS. 5-repetition sit-to-stand test in subjects with chronic stroke: reliability and validity. Arch Phys Med Rehabil. 2010;91: 407-13.
16. Lomaglio MJ, Eng JJ. Muscle strength and weight-bearing symmetry relate to sit-to-stand performance in individuals with stroke. Gait Posture. 2005;22: 126-31.

17. Clarkson H. Musculoskeletal Assessment. Philadelphia: Lippincott Williams \& Wilkins; 2000 .

18. Wellmon R. Gait assessment and training. In: Cameron MH, Monroe L, editors. Physical Rehabilitation. St. Louis: Elsevier; 2007.

19. Ade E, Smith Jr AR, Spigel PM. A case report: application of the upright motor control test on physical therapy intervention of an individual following a stroke. Physiother Theory Pract. 2012;28:317-25.

20. Hislop HJ, Montgomery J. The upright motor control test. In: Hislop H, Montgomery J, editors. Daniels and Worthingham's Muscle Testing: Techniques of Manual Examination. 8th ed. Philadelphia: WB Saunders; 2007.

21. Keenan MA, Perry J, Jordan C. Factors affecting balance and ambulation following stroke. Clin Orthop Relat Res. 1984;182:165-71.

22. Sweeney JK, Smutok MA. Vietnam head injury study: preliminary analysis of the functional and anatomical sequelae of penetrating head trauma. Phys Ther. 1983;63:2018-25

23. Trueblood PR, Walker JM, Perry J, Gronley JK. Pelvic exercise and gait in hemiplegia. Phys Ther. 1989;69:18-26.

24. Hamilton M, Williams G, Bryant A, Clark R, Spelman T. Which factors influence the activity levels of individuals with traumatic brain injury when they are first discharged home from hospital? Brain Inj. 2015;29:1572-80.

25. Vearrier LA, Langan J, Shumway-Cook A, Woollacott M. An intensive massed practice approach to retraining balance post-stroke. Gait Posture. 2005;22: 154-63.

26. Chitra J, Mishra S. Effect of compelled body weight shift therapy on weight bearing symmetry and balance in post stroke patients: an experimental prepost study. Int J Physiother Res. 2014;2:781-6.

27. Barto P, Gronley J, Perry J, Yoshida H. Correlation of clinical profile with gait parameters in the SCI population: a basis for FES patient selection? Proceedings of the Eighth Annual Conference on Rehabilitation Technology, United States of America; 1985

28. Italian Cooperative Research ICR2. Stroke and rehabilitation: Italian Cooperative Research (ICR2). Eur Med Phys. 2003;39:7-17.

29. Almarez MCR, Macatangay RMM, Santos NB, Flores MSE. Ergo bike-based locomotor training and leg ankle weights to enhance muscle strength and functional ambulation among patients with chronic hemiparetic stroke. Steth. 2010;4:50-68.

30. Ferrante S, Pedrocchi A, Ferrigno G, Molteni F. Cycling induced by functional electrical stimulation improves the muscular strength and the motor control of individuals with post-acute stroke. Eur J Phys Rehabil Med. 2008;44:159-67.

31. Ambrosini E, Ferrante S, Pedrocchi A, Ferrigno G, Molteni F. Cycling induced by electrical stimulation improves motor recovery in postacute hemiparetic patients: a randomized controlled trial. Stroke. 2011;42:1068-73.

32. Galea MP. Introducing clinimetrics. Aust J Physiother. 2005;51:139-40.

33. Kimberlin CL, Winterstein AG. Validity and reliability of measurement instruments used in research. Amer J Health-Syst Pharm. 2008:65:2276-84.

34. Portney LG, Watkins M. Foundations of Clinical Research: Applications to Practice. 3rd ed. New Jersey: Pearson Prentice Hall; 2009.

35. Mokkink LB, Terwee CB, Gibbons E, Stratford PW, Alonso J, Patrick DL, et al. Inter-rater agreement and reliability of the COSMIN (COnsensus-based Standards for the selection of health status Measurement Instruments) checklist. BMC Med Res Methodol. 2010;10:82.

36. Terwee CB, Mokkink LB, Knol DL, Ostelo RW, Bouter LM, de Vet HC. Rating the methodological quality in systematic reviews of studies on measurement properties: a scoring system for the COSMIN checklist. Qual Life Res. 2012;21:651-7.

37. Law M. Outcome Measures Rating Form and Guidelines. McMaster University CanChild Centre for Disability Research; 2004. https:/canchild.ca/en/ resources/137-critical-review-forms-and-guidelines. Accessed 1 October 2015

38. World Health Organization. ICF International Classification of Functioning, Disability and Health. Geneva: World Health Organization; 2001.

39. Mokkink LB, Terwee CB, Patrick DL, Alonso J, Stratford PW, Knol DK, et al. COSMIN Checklist Manual. EMGO Institute for Health and Care Research; 2010. http://www.cosmin.nl/images/upload/files/ COSMIN\%20checklist\%20manual\%20v9.pdf. Accessed 1 October 2015

40. Terwee CB, Bot SD, de Boer MR, van der Windt DA, Knol DL, Dekker J, et al. Quality criteria were proposed for measurement properties of health status questionnaires. J Clin Epidemiol. 2007;60:34-42. 
41. van Tulder M, Furlan A, Bombardier C, Bouter L. Updated method guidelines for systematic reviews in the Cochrane Collaboration Back Review Group. Spine. 2003;28:1290-9.

42. Wetzel JL, Ewing J, Boyle R, Erb K, Presby M, Stefancin C. Inter-tester and intra-tester reliability of the uprightmotor control test performed by novice examiners. Phys Ther. 1999;79:S17.

43. Joa KL, Kwon SY, Choi JW, Hong SE, Kim CH, Jung HY. Classification of walking ability of household walkers versus community walkers based on KBBS, gait velocity and upright motor control. Eur J Phys Rehabil Med. 2015; 51:619-25.

44. Perry J, Garrett M, Gronley JK, Mulroy SJ. Classification of walking handicap in the stroke population. Stroke. 1995;26:982-9.

45. Mercer VS, Freburger JK, Chang SH, Purser JL. Measurement of pareticlower-extremity loading and weight transfer after stroke. Phys Ther. 2009;89: 653-64.

46. Swets JA. Measuring the accuracy of diagnostic systems. Science. 1988;240: 1285-93.

Submit your next manuscript to BioMed Central and we will help you at every step:

- We accept pre-submission inquiries

- Our selector tool helps you to find the most relevant journal

- We provide round the clock customer support

- Convenient online submission

- Thorough peer review

- Inclusion in PubMed and all major indexing services

- Maximum visibility for your research

Submit your manuscript at www.biomedcentral.com/submit
Biomed Central 